\title{
Progressive resistance training in patients with shoulder impingement syndrome: literature review
}

\author{
L'allenamento progressivo con resistenza nei pazienti \\ con sindrome da conflitto. Revisione della letteratura
}

\author{
M. Cardoso de Souza, R. Trajano Jorge, A. Jones, I. Lombardi Júnior, J. Natour \\ Setor de Coluna Vertebral, Procedimentos e Reabilitação em Reumatologia, Disciplina de Reumatologia, \\ Universidade Federal de São Paulo, Escola Paulista de Medicina, SP, Brazil
}

\begin{abstract}
RIASSUNTO
La sindrome da conflitto e la tendinite della cuffia dei rotatori sono considerate le cause intrinseche più comuni di dolore ed incapacità nella spalla. Questa revisione affronterà i concetti generali della sindome da conflitto, cosi come l'allenamento progressivo con resistenza e $i$ vari interventi fisioterapici in questa malattia. L'obiettivo è rivedere in letteratura quanto trattato sull'allenamento progressivo di resistenza come approccio terapeutico nella sindrome da conflitto. Sono stati selezionati i test clinici controllati e randomizzati che valutassero l'uso dell'allenamento con resistenza nella Sindrome da Conflitto. Sono stati inclusi nella revisione articoli in portoghese ed in inglese. $\grave{E}$ stato trovato soltanto un articolo sull'argomento. Gli autori risaltano ancora la necessità della realizzazione di altri studi sul tema, dato che la tecnica viene ampiamente utilizzata in diverse altre patologie muscoloscheletriche.
\end{abstract}

Reumatismo, 2009; 61(2):84-89

\section{INTRODUCTION}

Tiser. he upper limbs perform diverse functions related to activities of daily living and labor activities. This occurs due to the considerable range of motion of the shoulder (1). The shoulder is a complex of muscles, bone articulations and functional articulations that allow greater mobility than in any other joint in the human body. However, this mobility is achieved at the cost of structural stability (2). Shoulder conditions are among the most common peripheral complications $(3,4)$. Activities that employ the arms or hands are known to increase the risk of the development of shoulder pain (3). It is estimated that the incidence of shoulder

Indirizzo per la corrispondenza:

Prof. Dr Jamil Natour

Disciplina de Reumatologia

Universidade Federal de São Paulo, UNIFESP/EPM

Rua Botucatu, 740

CEP: 04023-900, São Paulo, S.P., Brazil

E-mail: jnatour@unifesp.br problems ranges from 7 to 25 of every 1000 visits to general physicians (5). The prevalence of shoulder pain among adults under 70 years of age ranges from 7 and $27 \%$, whereas this prevalence is between 13.2 and $26 \%$ among individuals over 70 years of age (6).

The use of the shoulder most often occurs in flexion, with the hand in front of the body rather than to the side. When the arm is raised, a reduction in the subacromial space occurs. Shoulder impingement syndrome is characterized by shoulder pain that becomes exacerbated when the shoulder is raised or when the arms perform activities above the head. This pain is caused by the functional impairment of the subacromial structures: rotator cuff, long head of the biceps and bursa (7). Impingement syndrome and tendonitis of the rotator cuff are the most common intrinsic causes of shoulder pain and disability $(5,8)$.

Ischemia, inflammation and degeneration are related to age and overload on the tendons of the rotator cuff and are present in tendonitis of the rota- 
tor cuff $(9,10)$. The impact of the tendon sheath and subacromial bursa when the shoulder is raised increases pain and contributes toward long-term conditions (7). Anatomical and surgical observations have found that impingement occurs against the anterior margin and lower surface of the acromion, the coracoacromial ligament and, at times, the acromioclavicular joint (11).

Rotator cuff injury is classified in three stages:

1. edema and hemorrhaging, which may be the result of the excessive use of the arm above shoulder level and generally occurs in sports and labor activities (7);

2. fibrosis and tendonitis: along with tendonitis, with repeated episodes of inflammation, the bursa can become fibrotic and thickened. In this stage, shoulder function is satisfactory for mild activities, but becomes symptomatic for activities that raise the arms above shoulder level (7);

3. rotator cuff tear, tear of brachial biceps and bone abnormalities: with the increase in impingement, there may be a complete or incomplete tearing of the rotator cuff, brachial biceps injury and bone abnormalities in the anterior region of the acromion and greater tuberosity of the humerus. A rotator cuff tear begins with repeated impingement rather than due to circulatory impairment or trauma to the shoulder (7). There are many forms of treatment for this disease, such as non-hormonal anti-inflammatory drugs, corticosteroid injection, oral corticosteroids, manipulation under anesthesia, physiotherapy, pneumoarthrography, surgery and extracorporeal shock wave therapy, but the efficacy of these methods is not yet well established $(12,13)$.

Numerous rehabilitation interventions are available for the treatment of shoulder injuries, including thermotherapy (ultrasound), transcutaneous electrical nerve stimulation (TENS) and exercise. There is considerable variety in the use of these treatments among healthcare professionals, but the efficacy of these interventions remains unclear (14).

\section{METHODS}

A literature review was carried out using the Lilacs, Medline, Pubmed and Web of Knowledge databases searching for studies published between 2000 and 2008. The following keywords were used: resistance exercises, exercises with weight, resistance training, strength training, painful shoulder, shoulder impingement syndrome, exercise and the trans- lations of these terms in Portuguese. Controlled, randomized clinical trials that assessed the use of resistance training on shoulder impingement syndrome were selected. Articles written in English and Portuguese were included.

\section{Scientific evidence of physiotherapy for shoulder impingement syndrome}

In 1997, a systematic review of controlled, randomized clinical trials involving physiotherapy for shoulder conditions concluded that the use of ultrasound therapy (compared to a placebo treatment) proved ineffective on patients with shoulder disorders. There is also insufficient evidence supporting the use of low-level laser therapy, cryotherapy, electrotherapy, exercise and mobilization on such patients. This suggests that future studies should stress the use of exercise and mobilization (15).

In 2001, a systematic review of rehabilitation interventions for shoulder pain was published, finding evidence indicating the use of ultrasound on calcifying tendonitis of the shoulder, but little evidence indicating the use of ultrasound for other shoulder conditions (capsulitis, bursitis and tendonitis). Regarding therapeutic exercise, thermotherapy, TENS, massage and biofeedback electromyography, there is little evidence for considering theses methods effective (16).

\section{Resistance training}

The interest in resistance training gained ground during World War II, when the importance of "progressive resistance exercise" was demonstrated in the improvement of muscle strength and hypertrophy in the rehabilitation of military personnel (17). In the 1950s and 60s, resistance training captured the interest of the medical, scientific and athletic communities (18).

Training with resistance exercises is defined as an activity that develops and maintains muscle strength, endurance and mass (19). Resistance training has been practiced by a large variety of individuals both with and without chronic disease, as it is associated to improvements regarding cardiovascular function $(20,21)$, metabolism, risk factors associated to coronary events, osteoporosis (22, $23)$, cancer $(24)$, diabetes $(25,26)$ and psychosocial wellbeing. The principal studies on resistance training involve both male and female individuals, including middle-aged and elderly individuals as well.

The majority of physiotherapy studies use resistance training (strengthening exercises with the use 
of weights and loads), but fail to demonstrate the calculation and progression of the loads. Therefore, the exercises are not yet prescribed in an adequate, standardized fashion and the studies do not explain the best manner to perform the training. This hinders arriving at a consensus regarding the exercises to be performed, type of strengthening, calculation of load, progression of load, number of repetitions and rest intervals.

Resistance training has emerged as an effective alterative for addressing this lack of standardization. The principal studies related to the subject have demonstrated innumerous benefits from this type of training in a variety of diseases and disabilities (27). Resistance training appears to be a safe, effective intervention for patients with muscle strength deficit, but further evidence is needed in order to determine whether this type of exercise can improve function and quality of life for patients. Regarding patients in the acute recovery phase or those with degenerative diseases, greater caution should be taken in the performance of exercises. It is important for researchers to define the exercise program clearly and it is suggested that the term "resistance training" be employed rather than "strengthening" (28).

Regarding the safety of this type of training, no studies found thus far have reported any type of complication that would compromise the inclusion of this type of training on individuals with illnesses. In this type of therapeutic exercise modality, load, amplitude, velocity, degree of effort, rest intervals, number of repetitions, number of sets, duration and frequency can all be controlled.

\section{Progression of training}

Progressive resistance training is the gradual increase of load during a training program, for which the healthcare professional should monitor patient tolerance to exercise and adapt the exercise accordingly. In order to achieve an increase in muscle strength as well as improvements in endurance and hypertrophy, the following items should be considered:

1) increase in local resistance;

2) number of repetitions;

3) speed of repetitions;

4) rest period;

5) training volume (number of repetitions $X$ resistance) (29).

The number of repetitions an individual can perform depends on external resistance, which is referred to as maximum repetition (MR) (30). Train- ing with load is generally described as specific maximum repetition. For example, $10 \mathrm{MR}$ indicates the load maximum is performed with 10 repetitions (31). In order to determine the load in resistance training, the following should be considered:

- an increase in load based on repetitions; for example: performing 8 repetitions with a heavy load or 12 repetitions with a light load;

- increase in load within prescription range; for example: 8 to $12 \mathrm{MR}$. Loads of 45 to $50 \%$ of 1 MR have been demonstrated to improve muscle strength in non-trained individuals (32). At least $80 \%$ of $1 \mathrm{MR}$ should be used to produce neural adaptation and improve strength during resistance training (33). However, a number of authors have found that training with 1 to $6 \mathrm{MR}$ (especially 5 to $6 \mathrm{MR}$ ) is best for increasing maximum dynamic strength, which can also be achieved with loads of 8 to $12 \mathrm{MR}$. The loads may vary, but greater loads maximize muscle strength $(34,35)$;

- training affects the neural system $(36,37)$, causes hypertrophy (38) and alters the hormonal system (39). Thus, when there is a need for a change in the training volume, there should also be a change in the number of exercises, number of repetitions or number of sets (33).

\section{Prescription of training}

The prescription of resistance training may vary depending on whether the objective is strengthening, hypertrophy, explosion or endurance. In order to achieve an improvement in muscle strength, isotonic exercises (concentric and eccentric) should be performed with a load between 60 and $80 \%$ of $1 \mathrm{MR}, 1$ to 3 sets with 8 to 12 repetitions, rest intervals of 1 to 2 minutes between sets and a frequency of 2 to 6 times per week. This strengthening prescription is used for healthy individuals (29).

Progressive resistance training in physiotherapy The term resistance training is little used in physiotherapy. The term strengthening is mentioned more in studies, but has received criticism for being a vague term that most often fails to define the type of strengthening used. A study carrying out a survey of reviews on resistance training found the use of this type of resource in different diseases, such as the following (28):

1) arterial hypertension: a reduction was found in both systolic and diastolic pressure;

2) chronic obstructive lung disease: improvement 
was found in the strength of the lower and upper limbs, but with no improvement in function and durability while walking or pedaling;

3) musculoskeletal diseases: improvement was found in extensor and flexor strength of the trunk, with a reduction in pain and an improvement in function among patients with chronic low back pain. A review addressing fractures found improvement in strength and function. For neck pain, one study found an improvement in strength, range of motion, function and pain; for osteoarthritis of the hip and knee, a reduction in pain was found;

4) neuromuscular abnormalities: two reviews addressing cerebral palsy found an improvement in muscle strength, with no worsening of spasticity, but no conclusions were drawn regarding function and gait. For stroke victims, two reviews found an improvement in muscle strength, with no evidence of a worsening of spasticity or flexibility and no improvement in function;

5) gerontology: five systematic reviews found little change in lean mass and bone density of the femur. Improvements in bone density of the spine and distal radius were found in some studies, but adverse effects were either not controlled well or not reported.

\section{Progressive resistance training and shoulder impingement syndrome}

Exercise is known to be as effective as surgery for grade II shoulder impingement syndrome (15). In a systematic review published in 2003 on therapeutic exercise and manual therapy for shoulder impingement syndrome, the authors suggest some benefits for exercise or manual therapy when compared to acromioplasty, placebo or non-intervention. The conclusion was that there is little evidence to support or not support the efficacy of therapeutic exercise or manual therapy in the treatment of shoulder impingement syndrome (40).

It is difficult to find articles in the literature that prove the efficacy of exercises for shoulder impingement syndrome and discuss how the exercises should be performed, duration, number of sets, number of repetitions and calculation of load. Some studies use shoulder strengthening exercises with elastic bands, which hinders the standardization of these exercises.

Only one controlled, randomized study was found using resistance training in the treatment of patients with shoulder impingement syndrome. The study was carried out by Lombardi Júnior et al. (2008) (41) and assessed patients with regard to pain, function, quality of life, goniometry and isokinetic strength as well as the number of anti-inflammatory pills and analgesics consumed. The patients were submitted to a resistance training program for the shoulder musculature, which was performed twice a week for two months. The primary objective was to investigate pain and function in patients with shoulder impingement syndrome submitted to muscle strengthening exercises. The secondary objectives were to assess muscle strength and quality of life among these patients undergoing resistance training. Sixty patients were selected who fulfilled Neer's criteria for the diagnosis of shoulder impingement syndrome or tendonitis of the rotator cuff (Neer, 1983); tested positive on the Hawkins test (MacDonald et al., 2000) in at least the two previous months; and had pain between 3 and 8 on the numeric pain scale in the arch of motion that produced the greatest shoulder pain. $\mathrm{Pa}$ tients with a history of shoulder luxation, subluxation or fracture; cervical radiculopathy; degenerative joint disease of the glenohumeral joint; surgery on the shoulder, cervical spine or thoracic spine; inflammatory arthropathy; shoulder injections in the previous three months; and those who were performing any type of physical intervention for the shoulder were excluded from the study. Randomization was performed using a randomization table with confidential allocation, using opaque, sealed envelopes, and the patients were divided into experimental group and control group. Assessments were carried out prior to and at the end of treatment by a "blind" evaluator and consisted of the following instruments: visual analogue scale for pain at rest and during movement; Disabilities of the Arm, Shoulder and Hand (DASH) questionnaire for the assessment of function; SF36 (validated in Portuguese by Ciconelli et al. in 1999) for the generic assessment of quality of life; goniometry of the shoulder; and isokinetic assessment of the shoulder joint using an isokinetic dynamometer (Cybex 6000, Cybex - Division of Lumex, Ronkonhoma, New York). The patients in the experimental group were submitted to muscle strength assessment by maximum repetition (MR), in which the patient performed 6 repetitions with the maximal possible weight, thereby determining 6 maximum repetitions (6 MR) (Kraemer et al, 2002). Once the 6 MR load was determined, training was divided in the following manner: 2 sets of 8 repetitions, with the $1^{\text {st }}$ set at $50 \%$ of $6 \mathrm{MR}$ and 
the $2^{\text {nd }}$ set at $70 \%$ of $6 \mathrm{MR}$, always respecting the pain threshold of the patient. There was a 2 -minute rest period between the $1^{\text {st }}$ and $2^{\text {nd }}$ sets. The exercises were flexion, extension, medial rotation and lateral rotation of the shoulder. Training was carried out twice a week for a period of eight weeks. The $6 \mathrm{MR}$ was reevaluated every two weeks. The results demonstrated that the patients in the experimental group exhibited an improvement in pain at rest (from 4.2 to $2.4 ; \mathrm{p}<0.001$ ); pain during movement (from 7.4 to $5.2 ; \mathrm{p}<0.001$ ); function, as assessed by DASH (from 44.0 to $33.2 ; \mathrm{p}<0.007$ ); and some of the SF-36 domains when compared to the control group. Regarding the number of analgesics and non-hormonal anti-inflammatory pills, the control group used a greater number of pills than the experimental group and this difference was statistically significant at the end of the study. Howev- er, even though the control group used a greater number of pills, the members of this group did not experience improvement regarding pain.

From this study, we may conclude that progressive resistance training for the shoulder musculature in patients with shoulder impingement syndrome was effective in reducing pain as well as improving function and quality of life. Based on the classification criteria by level of evidence (PEDro) in the Physiotherapy Evidence Database, the use of progressive resistance training for shoulder impingement syndrome has a $1 \mathrm{~b}$ level of evidence, as there is one randomized, controlled trial of high quality (PEDro $\geq 6$ ). However, further well-designed studies are needed in order to improve the level of evidence that supports the use of progressive resistance training for patients with shoulder impingement syndrome.

\begin{abstract}
SUMMARY
Shoulder impingement syndrome and tendonitis of the rotator cuff are the most common intrinsic causes of shoulder pain and disability. The present literature review addresses general concepts on shoulder impingement syndrome as well as progressive resistance training and different physiotherapy interventions for this condition. The aim was to review what exists in the literature regarding progressive resistance training as a therapeutic approach to shoulder impingement syndrome. The review was carried out using the Lilacs, Medline, Pubmed and Web of Knowledge databases searching for studies published between 2000 and 2008. The following keywords were used: resistance exercises, exercises with weight, resistance training, strength training, painful shoulder, shoulder impingement syndrome, exercise and the translations of these terms in Portuguese. Controlled, randomized clinical trials that assessed the use of resistance training for shoulder impingement syndrome were selected. Articles written in English and Portuguese were included. Only one article on the subject was encountered. The authors stress the need for further studies on this topic, as the method has been widely used on a number of other musculoskeletal disorders.
\end{abstract}

Parole chiave - Sindrome da conflitto, esercizio, allenamento progressivo con resistenza, fisioterapia, riabilitazione. Key words - Shoulder impingement syndrome, exercise, resistance training, physiotherapy, rehabilitation.

\section{REFERENCES}

1. Schenkman M, De Cartaya VR. Kinesiology of the shoulder complex. J Orthop Sports Phys Ther. 1987; 8: 438-50.

2. Lehmkuhl LD, Smith LK. Brunnstron - cinesiologia clínica. Quarta edição, editora Manole, São Paulo, 1989.

3. Lo YP, Hsu YCS, Chan KM. Epidemiology of shoulder impingement in upper arm sports events. Br J Sports Med 1990; 24: 173-7.

4. Chard MD, Hazleman BL, King RH, Reiss BB. Shoulder disorders in the elderly: a community survey. Arthritis Rheum 1991; 34: 766-9.

5. Van der Windt DA, Koes BW, De Jong BA, Bouter LM. Shoulder disorders in general practice: incidence, patient, characteristics, and management. Ann Rheum Dis 1995; 54: 959-64.
6. Luime JJ, Koes BW, Hendriksen IJM, Burdof A, Verhagen AP, Miedema HS, et al. Prevalence and incidence of shoulder pain in the general population; a systematic review. Scan J Rheum 2004; 33: 73-81.

7. Neer CS II. Impingement lesions. Clin Orthop 1983; 173: 70-7.

8. Herberts P, Kaderfors R, Andersson G, Petersen I. Shoulder pain in industry: an epidemiological study on welders. Acta Orthop Scand 1981; 52: 299-306.

9. Jãrvholm U, Palmerud G, Herberts P, Hogfors C, Kaderfors R. Intramuscular pressure and electromyography in the supraspinatus muscle at the shoulder abduction. Clin Orthop Relat Res 1989; 245: 102-9.

10. Fu FH, Harner C, Klein H. Shoulder impingement syndrome. Clin Orthop Relat Res 1991; 269: 162-73.

11. Neer CS II. Anterior acromioplasty for the impingement syndrome in the shoulder. A preliminary report. J Bone Joint Surg 1972; 54: 41-50. 
12. Harniman E, Carette S, Kennedy C, Dorcas B. Extracorporeal shock wave therapy for calcific and noncalcific tendonitis of the rotator cuff: a systematic review. J Hand Ther 2004; 17: 152-64.

13. Green S, Buchbinder R, Glazier R, Forbes A. Interventions for shoulder pain (Cochrane Review). In: Cochrane Library: Issue 1, Update software, 2004.

14. Johansson K, Adolfsson L, Foldevi M. Attitudes toward management of patients with subacromial pain in Swedish primary care. Fam Pract 1999; 16: 233-7.

15. Van der Heijden GJMG, Van der Windt DAWM, de Winter AF. Physiotherapy for patients with soft tissue shoulder disorders: a systematic review of randomised clinical trial. Br Med J 1997; 315: 25-30.

16. Philadelphia Panel. Phys Ther 2001; 81: 1719-30.

17. Delorme TL. Restoration of muscle power by heavyresistance exercises. Journal Bone Joint Surgery 1945; 27: 645-67.

18. Berger R. Effect of varied weight training-programs on strength research quarterly. Res Q 1962; 33: 168-81.

19. Graves JE, Franklin BA. Treinamento resistido na saúde e reabilitação. Rio de Janeiro: Ed Revinter; 2006.

20. Hare DL, Ryan TM, Selig SE, Pellizzer AM, Wrigley TM, Krum H. Resistance exercise training increases muscle strength, endurance, and blood flow in patients with chronic heart failure. Am J Cardiol 1999; 83: 1674-7.

21. Parker ND, Hunter GR, Treuth MS, Kekes-Szabo T, Kell SH, Weinsier R, White M. Effects of strength training on cardiovascular responses during a submaximal walk and a weight-loaded walking test in older females. J Cardiopul Reha 1996; 16: 56-62.

22. Menkes A, Mazel S, Redmond RA, Koffler K, Libanati CR, Gundberg CM, Zizic TM, Hagberg JM, Pratley R, Hurley BF. Strength training increases regional bone mineral density and bone remodeling in middle-aged and older men. J Appl Physiol 1993; 74: 2478-84.

23. Ryan AS, Treuth MS, Rubin MA, Miller JP, Nicklas BJ, Landis DM, Pratley RE, Libanati CR, Gundberg $\mathrm{CM}$, Hurley BF. Effects of strength training on bone mineral density: hormonal and bone turnover relationships. J Appl Physiol 1994; 77: 1678-84.

24. Koffler KH, Menkes A, Redmond RA, Whitehead WE, Pratley RE, Hurley BF. Strength training accelerates gastrointestinal transit in middle-aged and older men. Med Sci Sports Exerc. 1992; 24415-9.

25. Miller JP, Pratley RE, Goldberg AP, Gordon P, Rubin M, Treuth MS, Ryan AS, Hurley BF. Strength training increases insulin action in healthy 50 to $65 \mathrm{yr}$ old men. J Appl Physiol 1994; 77: 1122-7.

26. Nicklas BJ, Ryan AJ, Treuth MS, Harman SM, Blackman MR, Hurley BF, Rogers MA. Testosterone, growth hormone and IGF-1 responses to acute and chronic resistive exercise in men aged 55-70 years. Int J Sports Med 1995; 16: 445-50.

27. Winett RA, Carpinelli RN. Potential health-related ben- efits of resistance training. Preventive Medicine 2001; 33: 503-13.

28. Taylor NF, Dodd KJ, Damiano DL. Progressive resistance exercise in physical therapy: a summary of systematic reviews. Phys Ther 2005; 85: 1208-23.

29. Kraemer WJ, Adams K, Cafarelli E, Dudley GA, Dooly C, Feigenbaum MS, et al. American College of Sports Medicine position stand. Progression models in resistance training for healthy adults. Med Sci Sports Exerc 2002; 34: 364-80.

30. Campos GE, Luecke TJ, Wenndeln HK, Toma K, Hagerman FC, Murray TF, et al. Muscular adaptations in response to three different resistance-training regime: specificity of repetition maximum training zone. Eur $\mathbf{J}$ Appl Physiol 2002; 88: 50-60.

31. Benson C, Docherty D, Brandenburg J. Acute neuromuscular responses to resistance training performed at different loads. J Sci Med Sport 2006; 9: 135-42.

32. Sale DG, Jacobs I, Macdougall JD, Garner S. Comparison of two regimens of concurrent strength and endurance training. Med Sci Sports Exerc 1990; 22: 348-56.

33. Hakkinen K, Alen M, Komí PV. Changes in isometric force- and relaxationtime, electromyographic and muscle fiber characteristics of human skeletal muscle during strength training and detraining. Acta Physiol Scand 1985; 125: 573-85.

34. Macdougall JD, Ward GR, Sale DG, Sutton JR. Biochemical adaptation of human skeletal muscle to heavy resistance training and immobilization. J Appl Physiol 1977; 43: 700-3.

35. Staron RS, Karapondo DL, Kraemer WJ, Fry AC, Gordon SE, Falkel JE, et al. Skeletal muscle adaptations during early phase of heavy-resistance training in men and women. J Appl Physiol 1994; 76: 1247-55.

36. Hakkinen K, Komi PV, Alen M, Kauhanen H. EMG, muscle fiber and force production characteristics during a 1 year training period in elite weightlifters Eur J Appl Physiol 1987; 56: 419-27.

37. Hakkinen K, Pakarinen A, Alen M, Kauhanen H, Komi PV. Neuromuscular and hormonal adaptations in athletes to strength training in two years. J Appl Physiol 1988; 65: 2406-12.

38. Tesch PA, Komi PV, Hakkinen K. Enzymatic adaptations consequent to Long-term strength training. Int J Sports Med 1987; 8 (Suppl 1): 66-9.

39. Raastad T, Bjoro T, Hallen J. Hormonal responses to high- and moderate intensity strength exercise. Eur J Appl Physiol 2000; 82: 121-8.

40. Desmeules F, Côté CH, Frémont P. Therapeutic exercise and orthopedic manual therapy for impingement syndrome: A systematic review. Clin J Sport Med 2003; 13: $176-82$.

41. Lombardi I Jr, Magri AG, Fleury AM, Da Silva AC, Natour J. Progressive resistance training in patients with shoulder impingement syndrome: a randomized controlled trial. Arthritis Rheum 2008; 59: 615-22. 